\title{
PENYULUHAN PEMBERDAYAAN WANITA MELALUI EKONOMI KREATIF DI RT 02/ RW 07 TANAH GARING DESA SOKARAJA TENGAH KECAMATAN SOKARAJA KABUPATEN BANYUMAS JAWA TENGAH
}

\author{
Pusporini Palupi $\mathbf{J}^{1}$, Jamaludin ${ }^{2}$, Elizabeth Tika $\mathbf{K}^{3}$, Edy Krisyanto ${ }^{4}$, Yeni Septiani ${ }^{5}$ \\ Universitas Pamulang \\ email: dosen01399@unpam.ac.id
}

\begin{abstract}
The purpose of Community Service Activities is to carry out one of the Tri Dharma of Higher Education, especially in Pamulang University. Also, it is hoped that with this community service, the existence of universities can contribute to the development of a scientific application to the community. The method used in community service is conveying material verbally in this implementation, the material in counseling contains how to find out how to create more space for women who want to try to develop themselves through productive efforts other benefits of empowering women through the creative economy by utilization of natural wealth So as an effort to empower women in improving the economy of the PKK group and village communities. The community service obtained is an activity carried out for the people of Central Sokaraja Village, the realization of awareness of the importance of entrepreneurship to improve the family economy, especially women, providing knowledge about the utilization of one of the potentials that exist in Central Sokaraja Village, namely horticultural food crops is a very important activity to improve The value of selling and marketing it globally is one of the advantages that can be obtained in improving the welfare of the community in the Central Sokaraja village of horticulture. can achieve equal progress with men, Improve the position and role of women in various fields of life. In the creative economy aspect, the government has been intensively developed, so that this PKM activity is in the framework of scientific development on the creative economy of society to improve its economy. This activity aims to increase the economic productivity of women in the use of local economies for the development of organic plants by providing counseling. It is hoped that the knowledge gained in community service will provide insight into the use of natural potential to optimize the role of women, especially in improving the family economy so that women can be independent, especially in Sokaraja Tengah Village, Sokaraja Banyumas District, Central Java.
\end{abstract}

Keywords: women's empowerment, economy, creative. 
Tujuan dari Kegiatan Pengabdian Kepada Masyarakat adalah untuk melaksanakan salah satu Tri Darma Perguruan Tinggi khususnya di Universitas Pamulang. Selain itu diharapkan dengan pengabdian kepada masyarakat tersebut keberadaan perguruan tinggi dapat memberikan kontribusi kepada pengembangan penerapan keilmuan kepada masyarakat. Metode yang digunakan pada pengabdian kepada masyarakat ini penyampaikan materi secara verbal dalam pelaksanaan ini materi dalam penyuluhan berisi tentang bagaimana cara untuk mengetahui bagaimana Menciptakan ruang lebih besar bagi perempuan yang mau berusaha mengembangkan diri melalui usaha-usaha produktif manfaat lain dari pemberdayaan wanita melalui ekonomi kreatif dengan pemanfaatan kekayaan alam Sehingga sebagai upaya pemberdayaan kaum wanita dalam meningkatkan perekonomian kelopok PKK dan masyarakat desa. pengabdian masyarakat yang diperoleh adalah kegiatan yang dilaksanakan untuk masyarakat Desa Sokaraja Tengah terwujudnya kesadaran akan pentingnya berwirausaha untuk meningkatkan perekonomian keluarga pada khususnya kaum wanita, memberikan pengetahuan mengenai pemanfaatan salah satu potensi yang ada di Desa Sokaraja Tengah yaitu tanaman pangan hortikultura adalah kegiatan sangat penting untuk meningkatkan nilai penjualan dan memasarkannya secara global adalah salah satu keunggulan yang dapat diperoleh dalam meningkatkan kesehjahteraan masyarakat di Desa Sokaraja Tengah hortikultura, Hasil pengabdian masyarakat yang diperoleh adalah kegiatan yang dilaksanakan untuk masyarakat Desa Sokaraja Tengah adalah kegiatan untuk mengatasi Untuk meningkatkan status, posisi dan kondisi perempuan agar dapat mencapai kemajuan yang setara dengan laki-laki, Meningkatkan kedudukan dan peranan wanita di berbagai bidang kehidupan. Pada aspek ekonomi kreatif telah gencar dikembangkan oleh pemerintah, sehingga kegiatan PKM ini dalam rangka pengembangan keilmuan tentang ekonomi kreatif masyarakat untuk meningkatkan perekonomiannya. Kegiatan ini bertujuan meningkatkan produktivitas ekonomi kaum wanita dalam pemanfaatan ekonomi lokal terhadap pengembangan tanaman organik dengan memberikan penyuluhan. Ilmu yang diperoleh pada pengabdian masyarakat ini harapannya semakin memberikan wawasan mengenai pemanfaatan potensi alam untuk mengopltimalkan peran wanita khususnya dalam meningkatkan perekonomian keluarga sehingga kaum perempuan dapat mandiri khususnya Desa Sokaraja Tengah Kecamatan Sokaraja Banyumas Jawah Tengah.

Kata Kunci : Pemberdayaan Wanita, Ekonomi, Kreatif.

\section{A. PENDAHULUAN}

Pranaka dan Muljarto dalam Anwas (2013: 50), mengartikan bahwa pemberdayaan adalah suatu upaya untuk membangun eksistensi pribadi, keluarga, masyarakat, bangsa, pemerintah, negara, dan tata nilai dalam kerangka proses aktualisasi kemanusiaan yang adil dan beradab, yang terwujud diberbagai kehidupan politik, hukum, pendidikan, dan lain sebagainya. Pemberdayaan juga memiliki makna menghidupkan kembali tatanan nilai, 
budaya, dan kearifan lokal dalam membangun jati dirinya sebagai individu dan masyarakat. Pemberdayaan memiliki makna kesetaraan, adil, dan demokratis tanpa adanya tekanan atau dominasi dalam suatu komunitas atau masyarakat. Namun, dalam praktikya programprogram pemberdayaan yang ada sering kali mengalami permasalahan, salah satunya yaitu tidak meratanya program pemberdayaan yang diterima oleh masyarakat. Ekonomi kreatif merupakan konsep ekonomi baru yang memadukan informasi dan kreatifitas yang mengandalkan ide, gagsan,dan pengetahuan dari sumber daya manusia sebagai faktor produksi.

Menurut Teori Ekonomi Schumpeter, perkembangan ekonomi merupakan sumber kemajuan ekonomi secara historis, karena sejarah kemajuan ekonomi adalah sejarah perkembangan kreativitas manusia. Dari perkembangan ekonomi yang berasal dari kreatifitas dan kompetensi wiraswasta yang tercermin di dalam akatifitasnya, pertumbuhan ekonomi yang tinggi tidak akan dapat di hindarkan. Hal ini disebabkan adanya pola individu-individu yang memiliki model kreativitas (creativity capital) yang mereka pergunakan untuk menciptakan inovasiinovasi sehingga memiliki daya tawar yang tinggi dalam ekonomi berkelanjuatan. Besarnya jumlah perempuan pengusaha diharapkan akan mampu meningkatkan ketahanan ekonomi, karena akan mampu menciptakan lapangan kerja baru, menyediakan barang dan jasa baru dengan haraga yang lebih murah, dan mengurangi kemiskinan. Namun diluar $60 \%$ pelaku UMKM tersebut masih banyak perempuan yang kerentanan terhadap ekonominya sangat rendah.

\section{B. METODE PELAKSANAAN KEGIATAN}

Metode pelaksanaan kegiatan penyuluhan pemberdayaan wanita melalui ekonomi kreatif ini melalui pendekatan kelompok dan diskusi pada kegiatan ditekankan pada subsektor dengan pemanfaatan lahan untuk tanaman hortikultura ini guna menambah pengetahuan, keterampilan dan potensi yang ada pada wanita itu sendiri, penyampaian kegiatan penyuluhan ini melalui virtual zoom dikarenakan situasi covid 19 dan kebijakan pemerintah setempat sehingga diputuskan kegiatan PKM ini secara online.

\section{HASIL DAN PEMBAHASAN}

Hasil pelaksanaan PKM yang dilakukan pada, 07 Desember 2020 dengan peserta kelompok PKK dan Masyarakat Desa Sokaraja Tengah, Kecamatan Sokaraja Banyumas Jawa Tengah, bahwa pemberdayaan wanita melalui ekonomi kreatif ini dalam pemanfaatan potensi alam yang dimiliki salah satunya pemanfaatan lahan yang ada di lingkungan Desa Sokaraja Tengah khususnya memebrdayaakn wanita kelompok PKK dan masyarakat dalam upaya meningkatkan pengetahuan, keterampilan dan membantu dalam perekonomian keluarga. Dan ini diharapkan kaum wanita dapat mampu diberdayaan agar lebih kreatif dan juga terlatih memalui penyuluhan guna membuka juga pikiran pikiran bahwa potensi alam yang ada di Desa bisa menghasilkan nilai ekonomi.

1. Kegiatan yang dilaksanakan untuk kelompok PKK dan masyarakat Desa Sokaraja Tengah adalah kegiatan untuk mengembangkan potensi yang ada pada wanita sehingga mereka dapat mandiri dan terampil juga dapat membantu perekonomian dalam keluarga.

2. Masyarakat mendapatkan wawasan dengan materi yang di peroleh dari dosen-dosen manajemen Universitas Pamulang mengenai pemberdayaan wanita memalui ekonomi kreatif melalui pendekatan kelompok dan juga diskusi dengan penyampaian kegiatan penyuluhan ini memalui virtual zoom dikarenakan situasi covid 19 dan kebijakan pemerintah setempat sehingga diputuskan kegiatan PKM ini secara online . 
3. Respon dari kelompok PKK dan masyarakat Desa Sokaraja Tengah Kecamatan Sokaraja Banyumas - Jawa Tengah sangat antusias mengikuti vitrual zoom ini mereka sangat terbantu dengan adanya PKM dari para Dosen Manajemen Universitas Pamulang, menambah pengetahuan dan memotivasi kelompok PKK dan masyarakat terbantu lebih berdaya melalui pendekatan secara diskusi melalui media online via virtual zoom peningkatan pegetahuan kelompok PKK dan amsyarakat mengetahui pengembangan ekonomi kreatif salah satuya pada subsektor dalam pemanfaatan alam sekitar yaitu dengan pemanfaatan lahat dengan tanaman hortikultura dan inipun dapat menghasilkan nilai jual. Kelompok PKK dan masyarakat mengetahi potensi yang ada di Desanya yang banyak ditemukan yang bisa menjadi hasil bumi yang memiliki nilai ekonomis.

\section{KESIMPULAN DAN SARAN}

\section{Kesimpulan}

PKM dengan judul penyuluhan pemberdayaan wanita melalui ekonomi kreatif ini melalui penyuluhan dengan pendekatan kelompok dan diskusi merupakan PKM diharapkan dalam proses pemberdayaannya diharapkan pemberdayaan bisa berajalan dengan baik sesuai tujuan awal, dan pemberdayaan ini khususnya wanita kelompok PKK dan masyarakat menekankan pada pemanfaatan lahan untuk mengahsilkan sumber daya alam guna mengembangkan pengetahuan, keterampilan, dan potensi yang ada wanita digalih dan dapat menghasilkan sesuatu yang bernilai ekonomis Juga dapat mengaplikasikan agar dapat meningkatkan pendapatan keluarga.

\section{Saran}

Pelaksanaan kegiatan PKM ini diharapkan dapat berkembang lebih luas lagi khususnya dalam pemberdayaan kaum wanita melalui ekonomi kreatif dengan melakukan diskusi dan juga praktek dalam melibatkan pemerintah setempat ikut terlibat dalam jalannya kegiatan dalam pemberdayaan wanita guna menggalih potensi pada wanita agar dapat mandiri dan membantu perekonomian dalam keluarga.

\section{DAFTAR PUSTAKA}

Anwas, Oos M. (2013). Pemberdayaan Masyarakat Di Era Global. Bandung: Alfabeta.

Firdaus, Y., S. Sunarto., H. Nurcahyo., M. T. Ritonga., R. Arief., dan D. Suwandi. (2000). Pelajaran Akuntansi Untuk SMU. Edisi 1. Jakarta: Erlangga.

Hubeis, Aida. (2010). Pemberdayaan Perempuan dari Masa ke Masa. Bogor: IPB Press.

Kamil. (2010). Model Pendidikandan Pelatihan (Konsep dan Aplikasi). Bandung: Alfabeta.

Prijono,O.S., Pranarka,A.M.W. (2014). Pemberdayaan: Konsep, Kebijakan dan Implementasi. CSIS. Jakarta.

Suryana. (2013). Ekonomi Kreatif, Ekonomi Baru: Mengubah Ide Dan Menciptkan Peluang. Jakarta: Salemba Empat.

Tim Dunne dan Milja Kurki, (2013). International Relations Theories: Discipline and Diversity, Oxford: Oxford University Pers

Zubaedi. (2013). Pengembangan Masyarakat : Wacana dan Praktik. Jakarta: Prenadamedai Group.

https://www.cnnindonesia.com/gaya-hidup/20200729064745-277-529997/mengenal-macammacam-tanaman-hortikultura 
http://repository.unissula.ac.id/14960/5/Bab\%20I.pdf

http://digilib.unila.ac.id/11425/14/BAB\%20II.pdf https://www.pertanian.go.id/home/?show=page\&act=view\&id=61

https://www.cnnindonesia.com/gaya-hidup/20160526032604-262-133498/konsumsi- buahindonesia-paling-rendah-se-asia

http://repository.upi.edu/33054/9/T_PKN_1502641_Bibliography.pdf 